\title{
The Development of Online-Based Microteaching Learning in Improving the Teaching Basic Skills in the Covid Era 19
}

\author{
Eri Sarimanah*, Roy Efendi \\ Indonesian Language and Literature Study Program, FKIP \\ Universitas Pakuan \\ Bogor, Indonesia \\ *erisarimanah@unpak.ac.id
}

\author{
Figiati Indra Dewi \\ Indonesian Language and Literature Study Program, FKIP \\ Universitas Kuningan \\ Kuningan, Indonesia
}

\begin{abstract}
The Covid-19 pandemic era has led and changed a variety of life settings, including the world of education and learning. Face-to-face learning in class is no longer possible and changes into online-based distance learning. Microteaching class is no exception. The lecturer now must change the way to see the skills of how students teach, manage classes, ask questions, provide reinforcement, use variations, guide small groups, open and close the class. Yet, changing the conditions does not change the essence and content of the core goals of lectures. This research aims to develop online-based Microteaching learning in improving basic teaching skills in the era of covid-19 pandemic. In addition, it aims to find out the stages of activities that students must pass in making microteaching class happen. This research applied the Research and Development method from Borg and Gall, to determine the effectiveness and efficiency of the model. The research results showed that the development of online-based Microteaching learning in improving basic teaching skills in the Covid-19 era was needed by the student-teachers. Structurally, this learning model is feasible, relevant, and in accordance with the rules of developing learning models, both in terms of substance, and the structure of the model. Based on the results of the trials with experimental research designs (experimental and control classes), online-based Microteaching model is effective to be used to improve basic teaching skills.
\end{abstract}

Keywords—microteaching learning, online-based, basic teaching skills

\section{INTRODUCTION}

Micro teaching is a training method of basic teaching skills for student-teachers which is carried out in micro or simplified way, both in terms of time, material and number of students [1]. Micro teaching is usually carried out by student-teachers who exchange roles in practicing to master basic teaching skills, practice learning activities and discussing problems found. When students play a role as teachers, other students play a role as students.

Micro teaching is a practice method designed in such a way to improve teaching skills of student-teachers and develop teacher professional experience, especially teaching skills [2]. In practice, students apply a learning model with a syntax that emphasizes on student learning activities. The substance of the material presented is the material selection according to the 2013 Curriculum, namely text-based learning. The pattern used is to simplify or minimize aspects of learning such as the number of students, time, teaching materials and the application of certain teaching skills, so that teachers can tell the strengths and weaknesses of the student-teachers accurately.

The era of the Covid-19 pandemic that has swept across the world has changed the share of arrangements and habits and the design of lectures that have been taking place face- toface. In teaching Microteaching class in higher education, the field of teacher training is usually full of teaching practices and the implementation of Basic Teaching Skills, which is done by seeing face-to-face practice, now has to change to a virtual online pattern. This condition does not diminish the goals and quality of learning, but requires new patterns or breakthroughs so that activities with all their aspects do not stop, hampered by a pandemic. For this reason, an online-based Microteaching learning development design is needed.

In addition to training the ability of student-teachers to master the material, basic teaching skills are also very close to activities to instill the soft skills of student-teachers. How attitudes, movements, speech and motivation of studentteachers in implementing Basic Teaching Skills, such as opening and closing lessons, explaining, asking, using variations, managing classes, providing reinforcement, guiding small groups, managing classes, are practiced in helping student- teachers to be skillful teachers in the future.

The design of the online-based Basic Teaching Skill learning model is needed to meet the needs as an alternative when learning can no longer be held face-to-face. Changing this pattern must be done from the basic things from learning design, learning activities, to reflection on learning through discussion with a team of lecturers. It is done to make Student- 
teachers able to learn how to implement Basic Teaching Skill online.

\section{MethODS}

The method used in this study was Research and Development, by collecting information related to microteaching lectures in terms of preparation, implementation, and reflection. Regarding the need for learning models during the pandemic, starting with the development of an online-based microteaching learning model development design, model testing, model revision, final model and model dissemination [3]. In its implementation, the researchers used (1) descriptive, (2) evaluative, and (3) experimental techniques. The data about existing conditions were collected by using descriptive techniques. Evaluative techniques are used in evaluating the trial process of developing the product. The experimental method is used to test the efficacy of the resulting product. Two kinds of data, namely quantitative data and qualitative data were applied. Quantitative data were taken in the form of students' assessment scores on the criteria for needs in onlinebased microteaching learning. Qualitative data were obtained from the results of reflection on learning with lecturers and student-observers. The data on the needs of the online-based microteaching learning model came from students and lecturers who were taken through a questionnaire with a survey method. Respondent assessment data on the theoretical model design comes from experts in the field of education and learning which is collected through a study of model design and implementation of learning. The basic teaching skills test score data were obtained from the assessment of teaching activities. This is done to determine the effectiveness and efficiency of the model.

\section{RESULTS AND DISCUSSION}

Based on the results of testing the effectiveness of the model, an online-based microteaching learning model (OMLM) was created. The OMLM learning model emphasizes the ability of student-teachers in conducting basic teaching skills that cover managing classes, asking questions, providing reinforcement, using variations, guiding small groups, opening and closing a lesson. The online learning process for the resulting design products can be seen in figure 1 .

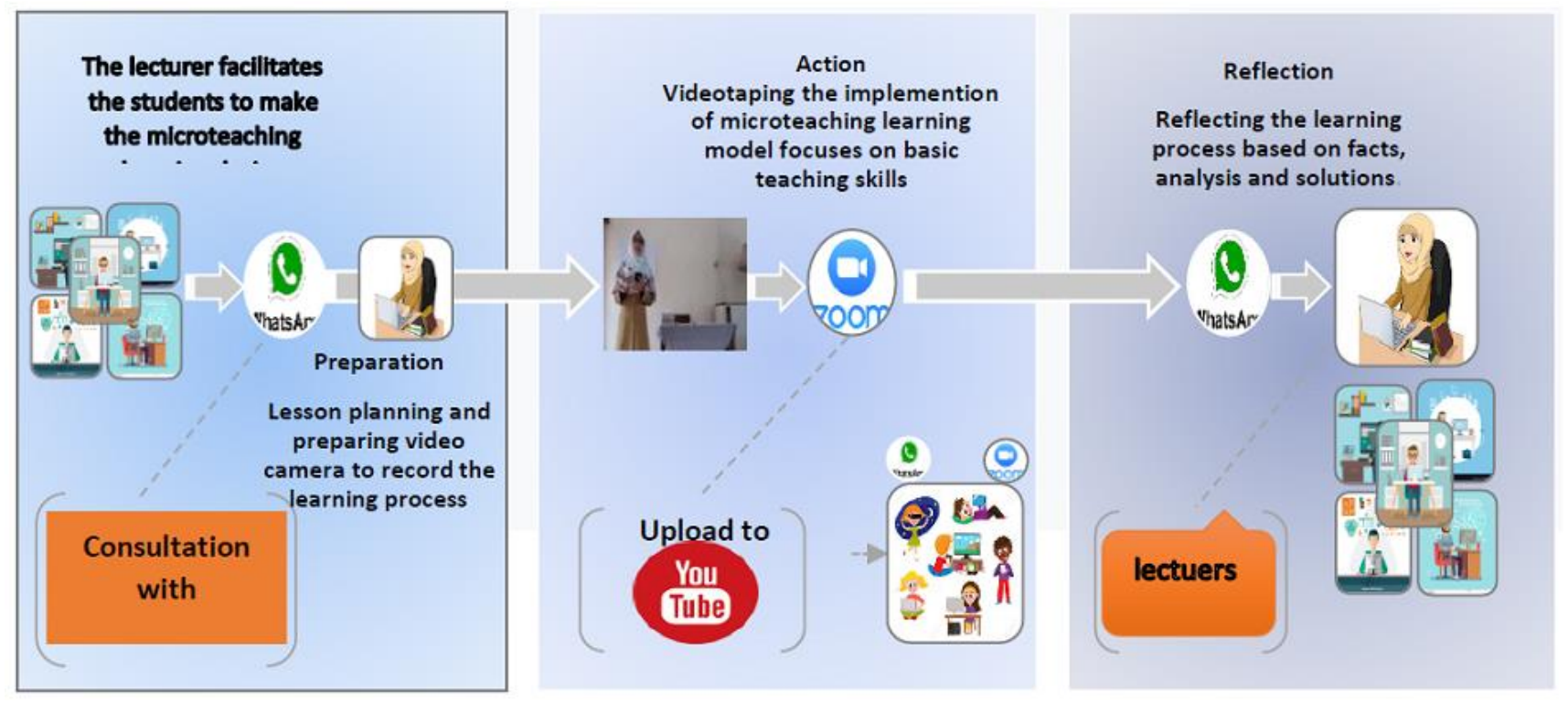

Fig. 1. Online-based microteaching learning model (OMLM)

From the research result, it was found that almost all of the basic teaching skills could be implemented well, $87.5 \%$. Only one basic teaching skill is difficult for $12.5 \%$ students to do, namely guiding small groups (Table 1). The findings obtained are based on the results of online and digital observations that online-based microteaching learning model can make students to be more focused, careful and enthusiastic, and creative because the learning outcomes are in the form of videos that must be uploaded on YouTube. They get experience and opportunities to develop their abilities on social media. Onlinebased microteaching lectures are a new experience for them; they get enlightened that they can enjoy the learning process, and are satisfied in producing the products. They involve themselves mentally to be active in interacting with the tasks for which they are responsible. They monitor the stages of their work. The learning design model based on metacognitive strategies is to provide new nuances and new experiences for students.

The online-based microteaching learning model has gone through a series of research activities to obtain a tested final product model. The learning was preceded by a pretest and ended in a posttest. After the t-test requirements are met with the results of the normality and homogeneity of the data, the ttest is carried out which shows that the pretest and posttest are 
significantly different. The pretest mean was 52.45 (standard deviation 6.5656), while the post-test mean was 77.14 (standard deviation 8.9695). The t-test result of 22.922 is greater than the value of t-table of 1.995. This indicates that the online-based microteaching learning model was effective to be done during the Covid-19 pandemic.

Basic teaching skills that cannot be implemented properly are skills to guide small groups. There are findings in onlinebased microteaching learning model activities that are difficult to do because it really requires closeness between the teachers and the students, such as strengthening movement to approach, shaking hands, cannot be carried out. However, most aspects of basic teaching skills as a training ground for student-teachers through online microteaching are still absolutely necessary.

Microteaching learning is still very much needed for student-teachers because many are equipped with many learning practices. The Covid-19 pandemic does not have to eliminate microteaching, but it needs to be designed according to the conditions experienced while still applying health protocols. Online-based microteaching learning can help the students practice the teaching skills such as explain, ask questions, provide reinforcement, use variations, manage classes, and open and close the class which begins with onlinebased learning design and discuss with peers online. The implementation of learning from home online is started with the zoom and YouTube application, ends with a reflection of online and digital learning. Thus, it can be concluded that the online-based microteaching learning model is effective and feasible to be used as an alternative model during the Covid-19 pandemic.

TABlE I. PERCENTAGE OF AVERAGE SCORE OF BASIC TEACHING SKILLS

\begin{tabular}{|l|l|l|}
\hline \multicolumn{1}{|c|}{ Statement } & \multicolumn{1}{|c|}{$\begin{array}{c}\text { Number of } \\
\text { Student }\end{array}$} & $\begin{array}{c}\text { Percentage } \\
(\mathbf{\%})\end{array}$ \\
\hline $\begin{array}{l}\text { Opening the class by stating the a-perception } 66 \\
\text { and objective }\end{array}$ & 92.8 \\
\hline $\begin{array}{l}\text { Explaining the materials systematically and in } 64 \\
\text { detail }\end{array}$ & 91.4 \\
\hline
\end{tabular}

\begin{tabular}{|l|l|l|}
\hline Asking with variety of questions & 62 & 88.6 \\
\hline Confirming verbally and non-verbally & 65 & 92.8 \\
\hline $\begin{array}{l}\text { Using variety of sounds, movements, } \\
\text { styles,and attention focus }\end{array}$ & 80 & 85.7 \\
\hline $\begin{array}{l}\text { Managing the class by organizing the students } \\
\text { and media }\end{array}$ & 57 & 81.4 \\
\hline $\begin{array}{l}\text { Guiding small group discussion } \\
\text { Closing the class with conclusion and } \\
\text { reflection }\end{array}$ & 36 & 94.3 \\
\hline
\end{tabular}

\section{CONCLUSION}

Microteaching learning is still very much needed for student-teachers because many are equipped with many learning practices. The Covid-19 pandemic does not have to eliminate microteaching, but it needs to be designed according to the conditions experienced while still applying health protocols. Online-based microteaching learning can help the students practice the teaching skills such as explain, ask questions, provide reinforcement, use variations, manage classes, and open and close the class which begins with onlinebased learning design and discuss with peers online. The implementation of learning from home online is started with the zoom and YouTube application, ends with a reflection of online and digital learning. Thus, it can be concluded that the online-based microteaching learning model is effective and feasible to be used as an alternative model during the Covid-19 pandemic.

\section{REFERENCES}

[1] J. Loughran, M.L. Hamilton, and J. Loughran, International handbook of teacher education. Springer, 2016.

[2] D.W. Allen and R.J. Clark, "Microteaching: Its Rationale," High Sch. J., vol. 51, no. 2, pp. 75-79, 1967.

[3] W.R. Borg and M.D. Gall, Educational Research: An Introduction. London: New York \& London: Longman, 1983. 